\title{
Drug use evaluation of ceftriaxone in medical ward of Dessie Referral Hospital, North East Ethiopia
}

\author{
Getasew A. Ayinalem*, Belayneh K. Gelaw, Abebe Z. Belay, Jimma L. Linjesa
}

Department of Pharmacy, College of Medicine and Health Sciences, Ambo University, Ambo, Ethiopia

Received: 14 October 2013 Accepted: 27 October 2013

*Correspondence to: Getasew A. Ayinalem, Email: getasewamogne@yahoo.com

(C) 2013 Ayinalem GA et al. This is an open-access article distributed under the terms of the Creative Commons Attribution Non-Commercial License, which permits unrestricted non-commercial use, distribution, and reproduction in any medium, provided the original work is properly cited.

\begin{abstract}
Background: Assessment of antimicrobial use can be performed by evaluating their use. Drug use evaluation is a performance improvement method that focuses on evaluation and improvement of drug use processes to achieve optimal patient outcomes. The objective of this study was to evaluate the rational use of ceftriaxone in Medical ward of Dessie referral Hospital, Dessie-Ethiopia.

Methods: Retrospective systematic study was used to assess rational use of ceftriaxone. The study was conducted by reviewing medication records of 316 patients, who received ceftriaxone during hospitalization at Medical ward of Dessie referral Hospital from December 30, 2011 to January, 2013. A systematic sampling method was used to select inpatient prescriptions in this ward with ceftriaxone and patient cards were located based on the medical record number on the prescription papers. Data was collected by using structured format and evaluated against WHO criteria for drug use evaluation as per standard treatment guideline of Ethiopia.

Results: Most patients were dosed as 2 g/day (79.4\%). The duration of therapy was found to be high in the range 2-7 days (51.69\%). Ceftriaxone was mainly used as pneumonia treatment $(38.8 \%)$. Maintenance fluids were the most commonly co-administered medications with a frequency of $62.16 \%$. The use of ceftriaxone was appropriate only in 170 cases $(55.8 \%)$ for the justification of use. Most of inappropriate uses were seen in terms of duration during treatment of pneumonia followed by frequency for the treatment of meningitis. Consistency of prescriber to the national standard treatment guideline was found to be low.

Conclusions: To improve rational use and prevent the development of resistance; prescribers should adhere to the national standard treatment guideline. Intensification of short term trainings and antibiotic control systems are some of the possible solutions the hospital has to do.ceftriaxone therapy does not meet the current STG of Ethiopia.
\end{abstract}

Keywords: Ceftriaxone, Drug use evaluation, Dessie, STGs (Standard treatment guidelines), DRH

\section{INTRODUCTION}

Infectious diseases are the most common causes of morbidity and mortality in developing countries. To control infectious diseases, antibiotics are used. Antibiotics represent approximately $30 \%$ of acute care hospitals during expenditure and they are prescribed for $20-50 \%$ of in patient. use of antibiotics has contributed to the dramatic fall in morbidity and mortality from communicable and infectious diseases over the last 50 years globally. However the control of infectious diseases is seriously threatened by the steady increase in the number of microorganisms that are resistant to antimicrobial agents. Emergence of antimicrobial resistance is the result of the use, over use and misuse of antibiotics. The increased prevalence of known resistant organisms and the emergence of newly resistant organisms have resulted in delays in effective therapy and the length of hospitalization and have led to increased cost for patients. When considering this, the logical first step is to evaluate the suitability of antibiotic usage. ${ }^{1}$ Antibiotic use evaluation is a basic measure for evaluating the appropriate usage of antimicrobial agents. To evaluate antibiotic usage DUE (Drug use evaluations) is implemented. ${ }^{2}$ 
DUE is a system of ongoing, systematic criteria based evaluation of drug use that will help to ensure medicines are used appropriately at the individual patient level. DUE may be applied to a drug therapeutic class, disease state or condition, a drug use process or outcome. DUE can assess the total process of medication prescribing, administration or dispensing. It involves comprehensive review of patients prescription and medication data before, during and after dispensing in order to assure appropriate therapeutic decision making and positive outcome properly developed if it is not only provides a means of identifying drug use problems but also provides a means to correct the problem and there by contribute to rational drug therapy. ${ }^{3-6,8}$

DUE is performed in patient settings to identify trends of over use and in appropriate prescribing. Surveys have shown that $22-65 \%$ antibiotic prescriptions are either in appropriate or in correct. When considering this, targeting antibiotics that are prescribed frequently for drug use evaluation would be important to extend the useful life of the antimicrobial agents. ${ }^{4}$

Cephalosporins are the most widely used antibiotics for treating common infections. These are large group of related beta-lactam antimicrobial agents with broad spectrum of activity, low rates of toxicity and ease of administration. Various cephalosporins are effective for treatment of many conditions, including pneumonia, skin and soft tissue infections, bacteremia and meningitis. ${ }^{11}$

They are classified by generation; first, second, third and fourth. In general lower generation cephalosporins have more gram positive activity and higher generation have more gram negative activity. Due to their activity against most gram negative organisms and their availability, $3^{\text {rd }}$ generation cephalosporins are most commonly used. Among $3^{\text {rd }}$ generation cephalosporins, ceftriaxone is the most prescribed drug. 6

Ceftriaxone is one of the most commonly used antibiotics due to its high antibacterial potency, wide spectrum of activity and low potential for toxicity. It is used to treat different types of bacterial infections, including bronchitis, pneumonia, bone infections, abdominal and skin infections, urinary tract infections etc. ${ }^{9}$

\section{Statement of the Problem}

Previous study showed that inappropriate use of antibiotics is central to limiting the development and spread of resistant bacteria in hospitals and community. ${ }^{(1)}$ In the world in appropriate use of ceftriaxone caused annual cost of infection caused by antibiotic resistant bacteria is estimated to be $\$ 4-5 \$$ million. ${ }^{7,8}$ This problem has been recorded in Africa hence use of broad spectrum antibiotics, in particular the $3^{\text {rd }}$ generation cephalosporins in nosocomial infection have been linked to the emergence of antibiotic resistance and increase in costs. ${ }^{5}$ DUE studies of ceftriaxone indicate its inappropriate use;
America $82 \%,{ }^{5}$ port of Spain $62 \%,{ }^{13}$ korea $65 \%,{ }^{4}$ black lion hospital $71.43 \%$, Adis abeba police hospital $63 \%$. $^{1,14}$ The appropriate use of ceftriaxone in Ayder referral hospital study was (35.8\%) was close to the result obtained in Port of Spain. ${ }^{16}$ All the above problem initiated study that indicate the inappropriate use of ceftriaxone in different hospitals.

\section{Objectives of the Study}

\section{General Objective}

$>$ To evaluate the use of ceftriaxone in Dessie referral hospital.

\section{Specific Objective}

$>$ To assess drug therapy meets in current standards

$>$ To identify medication related problem

$>$ To identify areas of in appropriate drug use

$>$ To identify areas in which further information and education may be needed by health care provider

\section{METHODS}

\section{Study Design}

Institution based retrospective survey was conducted to evaluate the use of ceftriaxone in Medical ward of Dessie referral hospital.

The criteria used for antibiotic selection include the following;

$\checkmark$ Ceftriaxone with risk of abuse

$\checkmark$ Those that were not being controlled by antibiotic prescribing restriction system.

$\checkmark$ Drug use evaluation will be performed by reviewing patient medication records

\section{Study area and period}

The retrospective study was conducted from March to June 2013, in DRH, Dessie, Ethiopia. Dessie is located in south Wollo zone of Amhara national Regional State, 401 kilometers away from Addis Ababa, the capital city of Ethiopia. One of the largest cities in Ethiopia based on figures from the central statistical agency in 2005, Dessie has an estimated total population of 169,104 of whom 86,167 are men and 82,937 are women. The woreda has an estimated area of 15.08 square kilometers, which gives the city a density of $11,213.79$ people per square kilometers.

Dessie referral hospital is the only referral hospital in Northeast Ethiopia. Among 165 health professionals are 13 specialists, 14 general practitioners, 3 Health officers, 6 anesthetists, 99 nurses (14 BSc. nurses, 80 diplomas, and 5 certificates), 12 mid wives ( 8 degree, 4 diploma), 12 pharmacists (3 degree, 9 diplomas) lab (6 degree, 7 
diplomas) and 15 (3 from dental, 5 ophthalmology, 5 radiography, 1 occupational health and 1 environmental health). There are different wards, among which medical ward is one which serves as the place of inpatient treatment and patient follow up.The ward has 10 rooms through each an average of 4 beds are located.

\section{Source of Population}

Medication record of patients who received ceftriaxone during hospitalization in medical ward of Dessie referral hospital from December 30 /2011-December 29/2012

\section{Study Population}

Medication records of patients who received ceftriaxone during hospitalization in Dessie referral hospital from December 30/2011-December 29/2012 and was included in the study using systematic sampling.

\section{Sampling Techniques}

The study used systematic sampling to select representatives of the population. Sampling started from separating prescriptions for the period December 30, 2011-December 29, 2012. Then in the patient prescriptions containing ceftriaxone for this period was counted and was found to be 3007 prescriptions. Then the card number of in patients from prescription containing ceftriaxone after starting prescription that was randomly chosen. Then from the card number every $8^{\text {th }}$ card numbers has been taken to sample the study population. The card numbers was used to locate the patient medication records.

\section{Sample Size Determination}

It was suspected $95 \%$ confidence interval was desired to estimate the proportion within $5 \%$ and the sample size drawn was

$$
\begin{aligned}
\mathrm{n} & =\mathrm{z}^{2^{*}} \mathrm{p}(1-\mathrm{p}) / \mathrm{w}^{2} \\
& =(1.96)^{2}(0.5 * 0.5) /(0.05)^{2} \\
& =385
\end{aligned}
$$

The above sample was going to be taken from a relatively small population $(<10,000)$, then the sample size has been adjusted as;

$$
\begin{aligned}
\mathrm{NF} & =\mathrm{n} /(1+(\mathrm{n} / \mathrm{N})), \\
& =385 /(1+(385 / 3007)) \\
& =342
\end{aligned}
$$

Then we took $10 \%$ of 342 as contingency value as the data was not filled correctly.

Finally a total no of 375 patient cards was calculated as sample size of the study. But from these patient cards 59 were incomplete and were excluded. Hence only 316 cards were analyzed.

\section{Data Collection}

The data was collected by using open filling in structured format and the data was recorded in the format from the patient medication records.

\section{Data Processing and Analysis}

The data was going to be processed and analyzed manually by using WHO criteria for drug use evaluation as per STGs of Ethiopia.

\section{Evaluation criteria}

Four WHO criterias for DUE were used in this study; namely, indication for use dosage frequency duration to evaluate ceftriaxone use.

\section{Study variables}

\section{Independent variables}

Age duration of treatment

Sex diagnosis

Dose frequency

\section{Dependant variables}

Drug use evaluation

\section{Inclusion criteria}

All patient cards recorded from only in medical wards that contained ceftriaxone.

Patients admitted to medical ward whose age is greater than or equal to 18 years.

\section{Exclusion criteria}

Patients admitted in medical wards whose age is below 18 years old.

Patients admitted in any other ward (pediatrics, surgery, emergency, and gynecology) who took ceftriaxone.

Patient records with insufficient information.

\section{Statistical Analysis}

The data was processed and analyzed by using WHO criteria for drug use evaluation as per standard treatment guideline of Ethiopia. Four WHO criteria namely indication for use, dosage, frequency and duration were used to evaluate ceftriaxone use. 


\section{Ethical consideration}

Approval and permission was sought from Ethical Review Board of College of medicine and health Sciences of Wollo University. An official letter of cooperation was written from the Department of Pharmacy to the respective departments, chief executive officers and chief clinical officers of the Dessie referral hospital, where the study was conducted. The issue of assuring privacy and confidentiality was given more attention.

\section{RESULTS}

A total of 316 patient cards out of 375 were found to have complete information for the intended purpose of ceftriaxone. Among the 316 patients, 151(47.8\%) were female and $165(52.2 \%)$ male. The average age of the patients was 34.3 (ranging 18 years to 83 years). Most of them were adults being in the range 18-65(85.8\%) (Table 1). In 201(76.6\%) cases, ceftriaxone was dosed as $2 \mathrm{~g} /$ day

Table 1: Age Distribution of patients included in the study.

\begin{tabular}{|ll|l|}
\hline Age (years) & Numbers\# & $\%$ \\
\hline $18-65$ & 271 & 85.8 \\
\hline$>65$ & 45 & 14.2 \\
\hline Total & 316 & $100 \%$ \\
\hline
\end{tabular}

Age distribution was biological classification (adults and geriatrics)

Table 2: Demographic (sex) distribution of patients included in the study.

\begin{tabular}{|lll|}
\hline Sex & Number\# & $\%$ \\
\hline Male & 165 & 52.2 \\
\hline Female & 151 & 47.8 \\
\hline Total & 316 & $100 \%$ \\
\hline
\end{tabular}

Table 3: Ceftriaxone daily dosing distribution (daily dosage gm/day).

\begin{tabular}{|lllll|}
\hline $\begin{array}{l}\text { Daily dosage } \\
\text { (gm/day) }\end{array}$ & 1gm & 2gm & 3gm & 4gm \\
\hline Frequency & 30 & 201 & 3 & 82 \\
\hline Percent & 9.5 & 63.6 & 0.9 & 25.9 \\
\hline
\end{tabular}

Table 4: Duration of ceftriaxone therapy distribution.

\begin{tabular}{|lll|}
\hline $\begin{array}{l}\text { Duration } \\
\text { in days }\end{array}$ & $\begin{array}{l}\text { Numbers of } \\
\text { patients }\end{array}$ & $\%$ \\
\hline Stat & 27 & 8.5 \\
\hline 1 day & 42 & 13.3 \\
\hline $2-7$ & 242 & 76.6 \\
\hline $8-14$ & 9 & 2.8 \\
\hline$>14$ & 4 & 1.3 \\
\hline
\end{tabular}

Mostly, ceftriaxone was given 1gm BID which covered 201(63.6\%), followed by $2 \mathrm{gm} \mathrm{BID}$ in the case of meningitis that covered $82(25.9 \%)$ and for a few cases $1 \mathrm{gm}$ TID $3(0.9 \%)$ was prescribed.

About $76.6 \%$ of ceftriaxone was given for medical ward patients for the period of 2-7 days, followed by $13.3 \%$ for 1 day. But the list percentage was $1.3 \%$ which showed ceftriaxone might be administered for greater than 14 days for a few cases.

Among the drugs co-administered with ceftriaxone, maintenance fluids were the most commonly used (32.1\%) (Table 5) followed by cimetidine $(31 \%)$, pethidine (10.7\%), diclofenac (9.4\%), plasil (4.4\%) Anti TB (3.1\%), etc.

Table 5: Frequently co-administered drugs with ceftriaxone.

\begin{tabular}{|lll|}
\hline Drug & $\begin{array}{l}\text { Frequency } \\
\text { (number) }\end{array}$ & $\%$ \\
\hline Mf & 304 & 32.1 \\
\hline Cimetidine & 294 & 31 \\
\hline Pethidine & 101 & 10.7 \\
\hline Diclofenac & 89 & 9.4 \\
\hline Furosemide & 31 & 3.3 \\
\hline Ant TB & 29 & 3.1 \\
\hline Cloxacillin & 29 & 3.1 \\
\hline Plasil & 42 & 4.4 \\
\hline PCM & 18 & 2.0 \\
\hline Others & 11 & 1.2 \\
\hline
\end{tabular}

The most common indication of ceftriaxone was pneumonia followed by meningitis, urinary tract infection, sepsis, AGE, typhoid fever and others (Table 6). 
Table 6: The most common diseases for which ceftriaxone was prescribed.

\begin{tabular}{|llllll|}
\hline Assessment & Total & Appropriate & $\%$ & Inappropriate & $\%$ \\
\hline Pneumonia & 115 & 66 & 57.4 & 49 & 42.6 \\
\hline Meningitis & 96 & 64 & 66.7 & 32 & 33.3 \\
\hline UTI & 66 & 26 & 39.4 & 40 & 60.6 \\
\hline Sepsis & 15 & 7 & 46.7 & 8 & 53.3 \\
\hline AGE & 12 & 6 & 50.0 & 6 & 50.0 \\
\hline Sexually transmitted diseases & 4 & - & 0 & 4 & 100 \\
\hline Typhoid fever & 3 & 1 & 33.3 & 2 & 66.7 \\
\hline IP & 3 & - & 0 & 3 & 100 \\
\hline Dyspepsia & 2 & - & 0 & 2 & 100 \\
\hline Total & 316 & 170 & & 146 & \\
\hline
\end{tabular}

Table 7: Distribution of inappropriate use of ceftriaxone based on DUE criteria.

\begin{tabular}{|lll|}
\hline DUE criteria & \# of error & $\%$ \\
\hline Duration & 69 & 47.3 \\
\hline Frequency & 35 & 24 \\
\hline Dose & 33 & 22.6 \\
\hline Indication & 9 & 6.2 \\
\hline Total & 146 & $100 \%$ \\
\hline
\end{tabular}

Among the 316 cases, 146(46.2\%) were found to be inappropriate (not according to the Ethiopian STG). While the rest $170(53.8 \%)$ were appropriate (Figure 1).

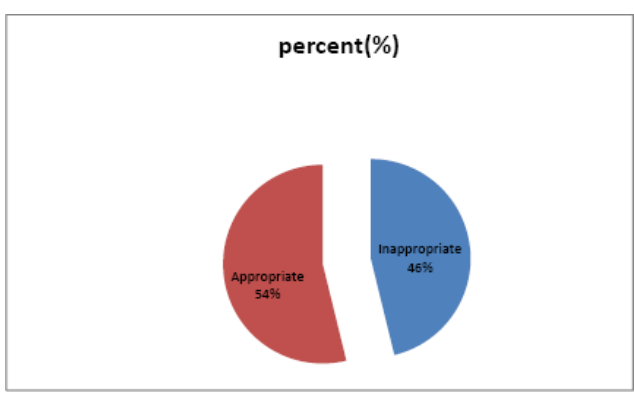

Figure 1: Appropriateness of ceftriaxone utilization in medical ward of DRH against the STG and WHO set criteria.

\section{DISCUSSTION}

In this study, the use of ceftriaxone was found to be appropriate for the justification of use in 170(53.8) which is lower than the value obtained in a retrospective evaluation conducted in Black lion Hospital, Addis Ababa (71.43\%), police Hospital, Addis Ababa(73.03), ${ }^{14}$ but higher than Ayder referral hospital, mekele Ethiopia(35.8\%). ${ }^{16}$ This difference might attributable to the fact that Black lion Hospital and Police hospital are well experience and have controlling agents like Drug therapeutic committee (DTC) and equipped with sufficient professionals. Infact Dessie referral hospital is long years of experience.

The appropriate use of ceftriaxone obtained in this study was also lower than that was obtained in the prospective drug use evaluation of ceftriaxone conducted in 10 Hospitals of Korea $(65.5 \%)$. This difference might attribute to the fact that the study conducted in Korea was prospective, evaluation of patients drug therapy before medication was dispensed and consider patient outcome which can be mentioned as one of the drawback of this study (retrospective). ${ }^{7,13}$

Additionally, the study in Korea used a number of criteria like culture and sensitivity test and other laboratory results, which were lacking in patient medical record of Dessie referral hospital. The appropriate use ceftriaxone in this study $(53.8 \%)$ was not close to the result obtained in Port of Spain, Trinidad $(38 \%)^{7,13}$ and Ayder referral hospital $(35.8 \%){ }^{16}$

The use of ceftriaxone was found to be high for the treatment of pneumonia $(49.05 \%)$ followed by meningitis $(30.38 \%)$, Urinary tract infection $(20.89 \%)$, sepsis (4.25\%), AGE (3.8\%), STI (1.27\%), Typhoid fever $(0.95 \%)$, IP $(0.95 \%)$ and dyspepsia $(0.63 \%)$.

This pattern was not similar in trend obtained in port of Spain, Trinidad, high for respiratory tract infection $(52.2 \%)$ and followed by UTI $(39 \%))^{7,13}$ But in Ayder referral hospital, Mekele, Ethiopia preoperative 
prophylaxis (followed by pneumonia $(21.28 \%)$ followed by sepsis $(20.94 \%)$, urinary tract infection (UTI) $(9.8 \%)$, meningitis $(4.73 \%)$ and typhoid fever $(2.7 \%){ }^{16}$

Most of the inappropriate use was involved during prescription of ceftriaxone for pneumonia and meningitis in duration and frequency $(43.3 \%)$ and $(24 \%)$ respectively. But in the treatment of STI and dyspepsia ceftriaxone was used $(6.2 \%)$ incorrectly. Because WHO did not show that ceftriaxone is used for the treatment of dyspepsia and STI. The high percent of in appropriate use in the treatment of these unrelated indication might account to the fact that ceftriaxone was not indicated. But for others adjustment of doses and duration might have been needed.

The mean duration of ceftriaxone therapy was found to be 6.8 days and high in the range 2-7days $(76.6 \%)$ followed by 1day therapy $(13.3 \%)$ which was lower than that obtained in Addis Ababa Black lion Hospital 9.2 days ${ }^{14}$ and even lower in the most in appropriate prescription area, Ayder referral hospital which was 7.2 days. ${ }^{16}$ This is an important factor as the number of days in which an antibiotics used correlates with resistance prevalence. ${ }^{1,3}$ Additionally, this may indicate the prevalence of diseases in which ceftriaxone was used in the range mentioned above.

Among the medication coadministered with ceftriaxone, maintenance fluids took first place with frequency of $304(32.1 \%)$ followed by cimetidine $294(31 \%)$, pethidine 101(10.7\%), plasil $42(4.1 \%)$. This really showed the co morbid condition of bacterial diseases with diseases for which the medication are indicated. Ceftriaxone was co administered with ringer lactate in case which was lower than that obtained in Black lion Hospital, Addis Ababa $(40.95 \%)$ and police lion Hospital, Addis Ababa $(44.48 \%)^{14}$ and Ayder referral hospital $(33.65 \%)^{16}$ which is close to this study. This low amount of maintenance fluid increases the probability of IV in compatibility of ceftriaxone with calcium containing drugs. This indicate the presence of medication related problem, namely IV incompatibility with respect to ceftriaxone use. ${ }^{9}$

\section{CONCLUSIONS}

Drug use evaluation of ceftriaxone with respect to indication, duration of therapy, and frequency of administration manipulates correct prescription practice.

In Dessie Referral Hospital as to WHO set criteria prescribers were not sticking to Ethiopian national STG. The majority of inappropriateness was seen with duration of therapy.

Result of the study showed that in appropriate use of ceftriaxone was high which paves away for the emergence of bacterial strains that are resistant to the available antimicrobial agent which in turn leads to increase in cost of therapy and treatment failure.

Hence we recommend the following:
Setting antibiotic control system.

Intensification of education and training programs.

Easy access of the national STG to all health professionals

Setting continuous drug use evaluation programs.

Hospital should have Drug therapeutic Committee (DTC) that can evaluate in correct prescription.

\section{ACKNOWLEDGEMENTS}

We are very grateful to our college staff members for unreserved guidance and constructive suggestions and comments from the stage of proposal development to this end. We would like to thank Wollo University for supporting the budget which required for this research. Finally our deepest gratitude goes to Dessie referral hospital staff workers who helped and allowed us in collecting and gathering data from the hospital.

\section{Funding: Wollo University}

Conflict of interest: None declared

Ethical approval: Approval and permission was sought from Ethical Review Board of College of Medicine and Health Sciences of Wollo University

\section{REFERENCES}

1. Food, Medicine and Health Care Administration and Control Authority (FMHACA), Ethiopia. Antimicrobial use, resistance and containment baseline survey, syntheses of findings, Aug 2009, Addis Ababa, Ethiopia.

2. Marion B, Tony M, Jonathan $\mathrm{G}$ et al. Ceftriaxone and cefotaxime use in Victorian hospitals, MJA, 2002; 176:524-529.

3. Romanan L, Zulfigar A, Adriano D et al. Disease control priorities in developing countries, Drug resistance, 2005; 1031-1051.

4. Hyuck 1, Dongsik J, Joon S et al. evaluation of ceftriaxone utilization at multi-center study, DOI: 10, 3904.Kjim, 2009.

5. American society of health system pharmacists, ASHP. Guideline on medication use evaluation. Am J Health system pharma 1996; 53:1953-5.

6. SHPA Standard of practice for drug use evaluation in Australian Hospital, J Pharm Pract Res 2004; 34(3):220-3.

7. The Academy of Managed Care Pharmacy's, concepts in managed care pharmacy. Drug use evaluation. Alexandria, 2008. Access date: 12/08/ 2011.http://www.amcp.org/workarea/downloadasse. aspx?id=9296.

8. WHO. Drug and therapeutic committee, A practical guide to drug use evaluation; Drug use evaluation (Drug utilization review), 2003; 155.

9. Irish medicine board. Ceftriaxone-contraindication in newborns and risk of calcium ceftriaxone 
precipitation when administered/mixed with solution containing calcium, New clinical, 2010.

10. David M. Promoting appropriate antimicrobial drug use: perspective from the center for disease control and prevention, Infectious disease society of America, Atlanta, 2007.

11. William F, Janis E. The cephalosporins, Mayo Clin Proc 1999; 74:187-195.

12. Christopher J, Denis B. Cephalosporins; A review, Pediatrics in review 2008; 29:264-273.

13. Laxtey M, Marjonne P, Hema R et al. Third generation cephalosporin use in a tertiary hospital in
Port of Spain, Trinidad: Need for an antibiotic policy, Biomed central, 2004.

14. Michael M, Mulugeta T, Comparative retrospective drug use evaluation of ceftriaxone injection in Police and Black lion Hospitals, EPA, 2009.

15. Jan E. Antibiotic utilization: Is there an effect on antimicrobial resistance? Chest, 2001: 119; 4285-4305.

16. Frehiwot Abebe, retrospective drug use evaluation of ceftriaxone in Ayder referral hospital, Ethiopia.

doi:10.5455/2319-2003.ijbcp20131208

Cite this article as: Ayinalem GA, Gelaw BK, Belay AZ, Linjesa JL. Drug use evaluation of ceftriaxone in medical ward of Dessie Referral Hospital, North East Ethiopia. Int J Basic Clin Pharmacol 2013;2:711-7. 